\title{
Finite Element Analysis of the Influence About the Space Between Bearing Expanded-Plate to the Bearing Capacity of Single Pile of the MEEP Pile
}

\author{
Yongmei Qian*, Xihui Wang and Ruozhu Wang
}

College of Engineering Jilin Jianzhu University, Changchun, Jilin, 130118, P.R. China

\begin{abstract}
In this paper, by ANSYS software it is built that a computer simulation analyzing model according to the finite element method, which is analyzed that the failure mechanism of the main pile and the soil around the bearing expandedplate of the Multi-Expanded-plates pile(the MEEP pile), it is qualitatively determined that the space between the bearing expanded-plates affect the bearing capacity of the single pile of the MEEP pile, and of which the lower limiting value is put forward, in order to provide the theoretical support to the actual design of the MEEP pile.
\end{abstract}

Keywords: The finite element method, the space between the bearing expanded-plates, the multi-expanded-plates pile (the MEEP pile), bearing capacity of the single pile, influence.

\section{INTRODUCTION}

From the structure of pile body and formation mechanism of the MEEP pile, it can be realized that this type of pile increase its bearing capacity of the single pile by addition of bearing expanded-plate. By research it is shown that there are many factors to affect the bearing capacity of the single pile of the MEEP pile, so the situation is very complex. The main factors include the diameter of the main pile, the diameter and height and position and form and space and quantity of the bearing expanded-plate, and so on [1]. In the process of the studying the bearing capacity of the single pile of the MEEP pile based on the sliding line theory, it can be found that due to space between bearing expandedplates of the MEEP pile has a great influence to the bearing capacity of the single pile, which ${ }^{1}$ is one of the main influence factors on the bearing capacity of the single pile. It is difficult to give a quantitative calculating formula to all of these factors, but qualitative conclusions can be done. In this paper, through the establishment of the finite element analysis model of the MEEP pile, it is analyzed that space between the bearing expanded-plates affect the bearing capacity of the single pile of the MEEP pile, in order to adequately consider its impact when the design of the MEEP pile and calculating the bearing capacity of the single pile.

\section{THE FINITE ELEMENT ANALYSIS OF THE SOIL FAILURE AROUND THE PILE}

In the process of studying of the failure mechanism of soil around the MEEP pile, it is to be analyzed the mechanism working together of pile and soil, through the finite element method. In order to study the working behavior of the soil surrounding the MEEP pile, it is

*Address correspondence to this author at the college of Engineering Jilin Jianzhu University, Changchun, Jilin, 130118, P.R.China;

Tel: 13504405206; E-mail: 654675316@qq.com established that the finite element calculating model of the work together of pile and soil, by the computer simulation analyzing, and is researched that the stress distribution surrounding the pile and up and down expanded-plate of pile.

\section{THE ESTABLISHMENT OF FINITE ELEMENT MODEL}

When constructing the computer model, the 8 node space unit is applied to establish the finite element calculation model (Fig. 1).
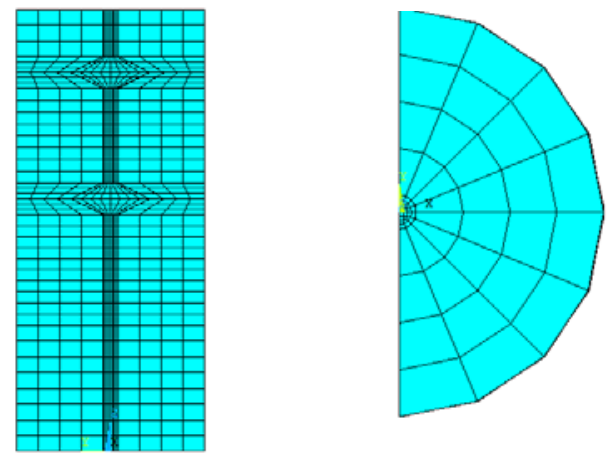

Fig. (1). The sketch map of the cell division of the pile.

According to the situation of being load, they are done that the cell division of the pile and the soil surrounding the pile, and refinement of unit for the node of junction surface between pile and soil [2]. In order to be beneficial to the analysis and comparison of computer model, and the principles of constructing models is determined as follows:

The concrete strength adopted of pile is $C 20$ (the density is $2.5 \times 10-5 \mathrm{~N} / \mathrm{mm} 3$, the elastic modulus $E=3 \times 104 \mathrm{~N} / \mathrm{mm} 2$, the Poisson ratio $\mu=0.167)$, the soil arranged surrounding the pile is often the cohesive soil. (The density is $2.0 \times 10-5$ 
$N / \mathrm{mm} 3$, the elastic modulus $\mathrm{E}=6 \times 10-2 N / \mathrm{mm} 2$, the Poisson's ratio $\mu=0.3$ ).

Due to mainly studying the failure mechanism of the soil up and down the bearing expanded-plate, and of which the effect on the bearing capacity of the single pile, and when the space of expanded-plates is appropriate, the failure of the soil up and down the plate doesn't affect each other, so one expanded-plate is temporarily set in the calculation model, the expanded-plate is set in different parts along the length of pile, such as the middle or near the top or near the bottom, and so on.

In the calculation model, in order to avoid the influence of boundary conditions to the soil, the range of soil surrounding the pile can not be too small, it is taken that a soil body with $7 \mathrm{~m}$ diameter and $12 \mathrm{~m}$ depth.

\section{THE ANALYSIS OF CALCULATING RESULT OF FINITE ELEMENT MODEL}

According to the principles above, computer models are established, now these computer models begin to be proceeded with computer simulation calculating, then it is obtained that the principal stress $\sigma_{x}$ and $\sigma_{z}$ of different models and shear stress $\tau x z$ of it $[3,4]$. To take the result of respectively models, it is formed that normal stress curve by the soil surrounding the model pile, which is as shown in Fig. (2).

As can be seen from the Fig. (2): nearby the bearing expanded-plate, within a certain range up the plate of the soil surrounding the pile, the tensile stress is generally developed, on the contrary, while within a certain range down the plate of the soil surrounding the pile, the compressive stress is increased. The increasing of value and the range of influence stress follows the increasing of the diameter of the bearing expanded-plate. The ratio of the length of influence range of tensile stress and the diameter of the expanded-plate is $0.65-0.75$.

By analyzing of the results and the curve above, making, the following conclusions is obtained: first, due to the bearing expanded-plate joined in, within a certain range of the upper plate, the soil surrounding pile develops tensile stress, which affects the effective length of the side-friction of pile, and makes the side-friction of pile decrease. Second, with the increase of the load, the range of increasing the normal stress down the plate decreases gradually, the soil under the top surface of the plate has generated the sliding failure, which is also made within a certain range of soil. This part of the side-friction of pile and the soil will also be reduced, therefore, which also affects the effective calculating length of the side-friction of pile.

\section{ANALYZING THE INFLUENCE OF THE SPACE BETWEEN THE PLATES.}

Due to the existence of the bearing expanded-plate, which make the soil up the plate generate tensile stress, the soil under the plate generate slip, thus make it decrease that the efficient calculating length of the side-friction of pile, therefore, different space between the bearing expandedplate have different stress behavior. The results show that, when the space between the bearing expanded-plate is larger, the overall stress behavior is as shown in (Fig. 3a) and (Fig. 3c), when the space between the bearing expanded-plate is smaller, then the overall stress behavior is as shown in (Fig. 3b) and (Fig. 3d).

As can be seen from Fig. (3): first, when the space between bearing expanded-plate is larger (much larger than the sum of the sliding area down the plate and the tensile stress area up the plate), the failure behavior of the soil at upper and lower plate will not be affected, still the same as pile with one plate, as shown in Fig. (3, a,c), $F=R_{1}+R_{2}+$ $R_{3}+F_{1}+F_{2}+F_{3}$, where $R_{1}$ and $R_{2}$ are calculated according to the sliding line theory, $F_{1}, F_{2}$ and $F_{3}$ are calculated according to the effective calculating length. Second, when the space between the bearing expanded-plate is smaller (less than the sum of the sliding area down the plate and the tensile stress area up the plate), there is a large impact [3]. At this point, the side-friction of pile $\mathrm{F}$ is assigned to three cylinders, as shown in Fig. (3, b,d), namely $F=F_{1}+F_{2}+$ $F_{3}+R_{1}+R_{2}$, where $R_{2}$ is calculated according to the sliding line theory, $\mathrm{F}_{1}$ and $\mathrm{F}_{3}$ are calculated by effective calculating length.

Through the statistic analysis of study results and a large number of practical engineering data, combining with
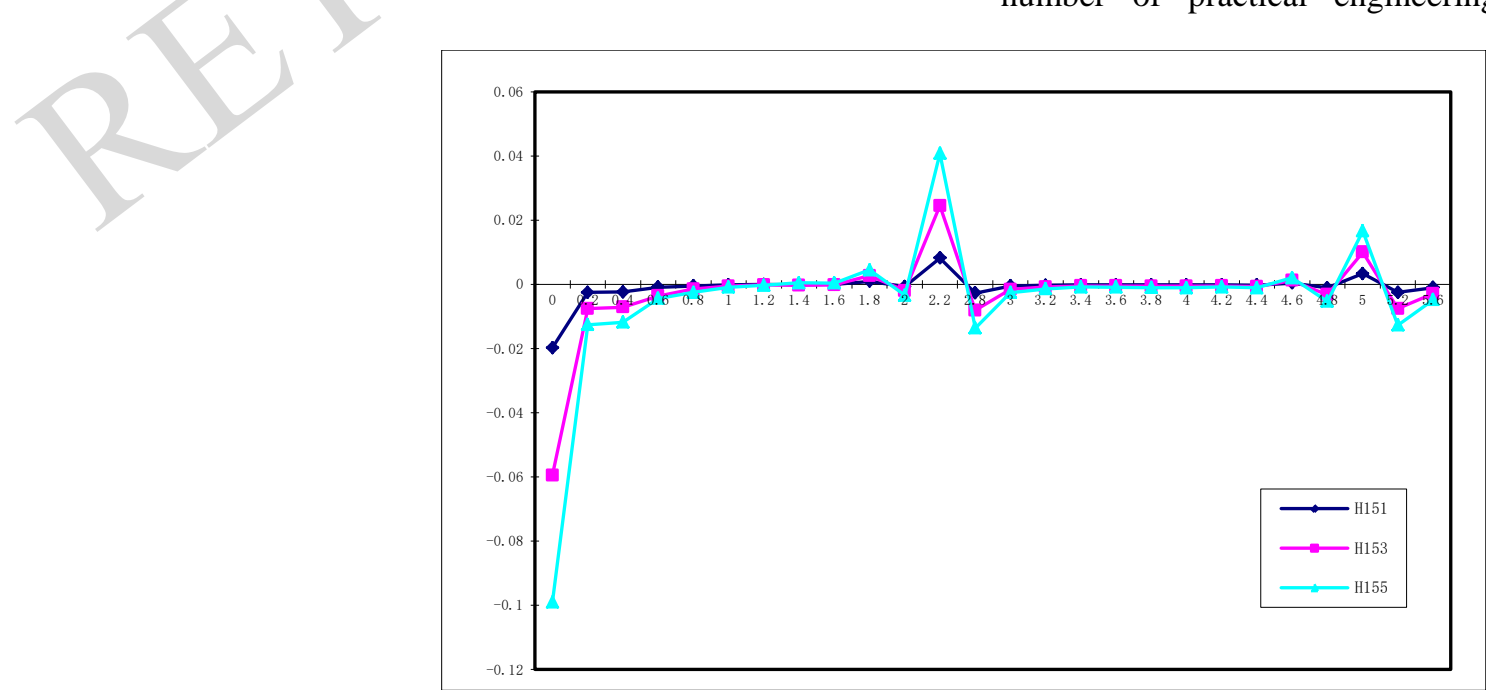

Fig. (2). The normal stress curve of the soil surrounding pile. 

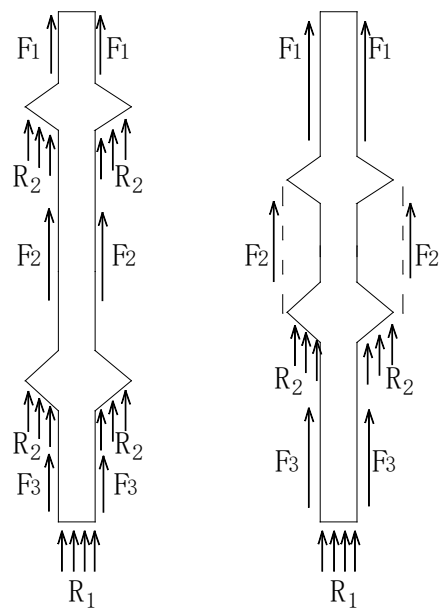

Fig.(3). The diagram of stress behavior of soil surrounding the pile.

relevant specifications of the concrete cast pile foundation codes, it is recommend that the lower limit of the space $\mathrm{S}$ between the bearing expanded-plates of the MEEP pile should be controlled as: in the clay, silt, $S \geq 2.5 D$, and sand, $S \geq 3.0 D$.

\section{CONCLUSION}

Synthesizing the analysis results above, it is obtained that the qualitative analysis conclusions about the choice of the space between the bearing expanded-plate, that is as follows:

Due to the existence of the bearing expanded-plate, in the soil surrounding the pile within a certain range of the upper plate, it is generates of tensile stress, which affects the effective length of the side-friction of pile, and makes the side-friction of the pile decrease. At the same time, due to the existence of the bearing expanded-plate, the soil up the plate generates tensile stress, while the soil down the plate generates slip, which makes the effective length of the sidefriction of pile decrease.

As for the MEEP pile, when the space between expanded-plates is reasonable, the interaction effect between the upper and lower plate is smaller, which basically conforms to the soil failure law of a pile with one plate, just the range of soil failure down the plate is smaller than that up the plate, it is explained that the upper plate bears the load earlier than the lower plate. When the space between expanded-plates is smaller, the interaction effect between the upper and lower plate is larger, because the space between expanded-plates closes to the range of the soil sliding line, soil failure are mainly the shear failure of the soil column of
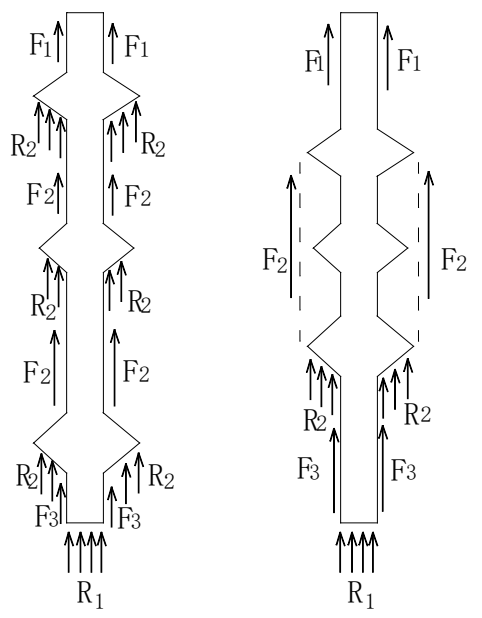

the fringe of plate, the soil between the plates has been unable to play its role fully. Therefore it is recommended that the lowest value of the space between the bearing expanded-plates of the MEEP pile should be controlled as: in the clay, silt, $\mathrm{S} \geq 2.5 \mathrm{D}$, and sand, $\mathrm{S} \geq 3.0 \mathrm{D}$. If the study results are applied to the actual design, which can play a better advantage of the MEEP pile, and help this technology applied widely and greater economic and social benefits will be created.

\section{CONFLICT OF INTEREST}

The authors confirm that this article content has no conflict of interest.

\section{ACKNOWLEDGMENTS}

This work is financially supported by National Natural Science Foundation of China (51278224).

\section{REFERENCES}

[1] M. Qian, X. S. Yin, R.Z. Wang, and J. Zheng, "The research of factors that influence on the ultimate bearing capacity of soil surrounding the concrete plates-expanded-Grouting pile”, Journal of Jilin Jianzhu University, vol. 21, pp. 14-16, 2004.

[2] W. J. Wang, Bottom-Expanded Pile Uplift Bearing Capacity Analysis, Henan University, China. 2010.

[3] Y. M. Qian, J.J. Ren, and X.S. Yin, "The simulated analysis in the computer on the effect of pile and soil working together about the Push-extend Multi-under-reamed Pile”, Advanced Material Research, vol. 479-481, pp. 59-64, 2012.

[4] Y. M. Qian, N. Mu, and R.Z. Wang, "The research about the method of establishing the model of limited unit about the pushextend multi-under-reamed pile”, Advanced Materials Research, vol. 671-674, pp. 602-605, 2013. 